\title{
Oil supply shocks and economic growth in the Mediterranean
}

\author{
Andrea Bastianin $^{\mathrm{a}}$, Marzio Galeotti ${ }^{\mathrm{b}}$, Matteo Manera ${ }^{\mathrm{c}, \mathrm{d}, *}$ \\ a University of Milan, Italy \\ ${ }^{\mathrm{b}}$ University of Milan, IEFE, Bocconi University, Milan, Italy \\ c University of Milan-Bicocca, Fondazione Eni Enrico Mattei, Milan, Italy \\ ${ }^{\mathrm{d}}$ University of Milan-Bicocca, Italy
}

\section{A R T I C L E I N F O}

\section{JEL:}

$\mathrm{C} 22$

E32

Q43

Keywords:

Oil supply shocks

Mediterranean countries

Economic growth

\begin{abstract}
A B S T R A C T
We study how oil supply shocks affect the output growth of selected countries in the Mediterranean region. We focus on the effects of oil supply shocks on economic activity, as measured by real gross value added, for the whole economy, as well as for specific industries. We show that the response of real gross value added growth is negative and often statistically significant for net energy importers, while for net energy exporters it is not distinguishable from zero. This result holds for the aggregate economies, as well as for the selected industries. Moreover, the effects of oil supply shocks increase with the degree of energy dependence in the Mediterranean countries belonging to the European Union. Our results have several policy implications. First, the European Union should encourage projects on the efficient use of energy in the Mediterranean area. Second, European financial markets should promote appropriate financial instruments to stimulate investments in the Mediterranean energy sector. Third, international investors should consider the country-specific reactions to major macroeconomic shocks in the Mediterranean region.
\end{abstract}

\section{Introduction}

Three continents, namely Europe, Asia and Africa, and twenty-one sovereign countries border the Mediterranean Sea. As of 2014 this area accounts for $11.9 \%$ of world Gross Value Added (United Nations Statistics Division).

The Mediterranean countries range from lower/middle income to high income (World Bank). Moreover political and social divides exist between countries on the North and the South Shore of the Mediterranean basin. These countries differ also in terms of their degree of energy dependence and energy intensity.

Precisely because of the heterogeneity in terms of economic growth, energy dependence, energy intensity and geopolitics of its constituent countries, the Mediterranean region represents a unique case-study for assessing the consequences of major macroeconomic shocks on countries which are economically, politically and geographically intertwined (Berument et al., 2010).

In this paper we concentrate on unexpected oil price changes driven by exogenous supply shortfall, one of the most important and widely investigated types of macroeconomic shocks.

On this respect, it is generally acknowledged that fluctuations in world oil prices affect countries' economies through several channels, such as, domestic price movements, aggregate and sectoral economic growth, energy markets (Hamilton, 2013). It is also well documented that positive oil price shocks tend to influence the economies of oilimporting countries differently than oil-exporting countries, and that, more generally, different countries have different reactions to oil supply shocks (Bastianin et al., 2016; Baumeister et al., 2010; Güntner, 2014; Jiménez-Rodríguez and Sánchez, 2005; Kilian, 2008b).

The literature on the economic effects of oil price shocks has traditionally focused on oil-importing countries, with specific attention to the US and selected economies belonging to the OECD (Bastianin and Manera, 2017; Kilian, 2008a; Jiménez-Rodríguez and Sánchez, 2005). However, more recently, several contributions have been published on the impacts of oil price shocks on the economies of oil-exporting countries. Specifically, studies are available for Canada, Denmark, Norway and the UK, as well as Asia (Cunado et al., 2015), Euroasia (Fakhri et al., 2017), Latin America (Santillán-Salgado and VenegasMartínez, 2015) and selected OPEC countries (Moshiri and Banihashem, 2012). A few papers have also investigated the Middle East-North Africa region (Berument et al., 2010).

Our study widens the extant literature on oil price shocks, at least in four directions. First, it analyzes countries which are generally underinvestigated. Second, it provides fresh evidence on how different economies react to exogenous oil supply shocks at both aggregate and industry levels. Third, it assesses the robustness of the empirical results

\footnotetext{
* Corresponding author at: University of Milan-Bicocca, Department of Economics, Management and Statistics, Via Bicocca degli Arcimboldi 8, 20126, Milan, Italy.

E-mail address: matteo.manera@unimib.it (M. Manera).
} 
to different measures of oil supply shocks. Finally, it addresses several research questions which are relevant for policy makers and global investors, among which: What is the relation between the effects of exogenous oil supply shocks, energy efficiency and energy dependence? Which industries are more exposed to exogenous oil supply shocks? Which countries are more affected by such shocks?

In this paper we answer these questions by modeling and estimating the responses to exogenous oil supply shocks during the period 1970-2015 of eight Mediterranean countries, Egypt, France, Greece, Israel, Italy, Morocco, Spain and Turkey, which are representative of different dimensions of heterogeneity (e.g. income levels and growth rates, degrees of energy dependence and energy intensity, levels of oil imports and exports) characterizing the Mediterranean basin. For each country, we focus on the effects of exogenous oil supply shocks on the economic activity of the whole economy, as well as of selected industries.

We measure exogenous oil supply shocks as the difference between the observed level of crude oil production and a counterfactual level of crude oil production, which proxies the shortfalls associated with strifes in the OPEC member states (Kilian, 2008a).

We show that most of the Mediterranean net energy importers experience a temporary decrease of the rate of growth of Gross Value Added. Oil supply shocks do not affect Gross Value Added when an high degree of energy intensity is compensated by a low degree of energy dependence. The effects of such shocks to Gross Value Added last, on average, five years when an high level of energy intensity is strengthened by a high level of energy dependence. The impacts of oil supply shocks on the Gross Value Added of the Mediterranean countries which belong to the EU do not exceed two years, on average.

Our findings confirm the need of a common, multi-dimensional, integrated economic policy for the whole Mediterranean region, which can contrast the contractionary effects of oil supply shocks by jointly considering the between-country and within-country differences in terms of economic development, energy intensity and energy dependence. ${ }^{1}$ These differences explain why energy integration is high in the policy agenda of Mediterranean countries. In particular, the relationships between the EU and countries in the Middle East-North Africa region are strategically important for providing a secure supply of energy to EU member states, whose economies are highly dependent on imported crude oil and natural gas. ${ }^{2}$

On this respect, our results have several policy implications. First, the EU should rethink its policy approach in the Mediterranean region and encourage projects on the efficient use of energy in the area. Second, European financial markets should promote specific financial instruments to stimulate investments in energy efficiency projects. Third, international investors should consider the reactions of each Mediterranean country to major macroeconomic shocks.

The rest of the paper is organized as follows. Section 2 describes the dataset, presents a brief description of the relevant statistics for the selected Mediterranean countries, and illustrates the measure of exogenous oil supply shocks adopted in the analysis. Section 3 discusses the methodology. Results are presented in Section 4. Section 5 illustrates some policy implications.

\footnotetext{
${ }^{\mathbf{1}}$ This suggestion is supported by recent research contributions (Aliboni, 2016; Alloisio et al., 2016; Hafner and Tagliapietra, 2016) and political declarations (UfM, 2016).

${ }^{2}$ In March 2011 the European Commission announced its commitment to establishing an "EU-South Mediterranean Energy Community" aimed at "promoting a real and reliable convergence of South Mediterranean partners' energy policies and EU policy" (the European Commission, p. 10, 2011). Tholens (2014), among others, thoroughly discusses the EU-South Mediterranean Energy Community.
}

\section{Data and the selected Mediterranean countries}

\subsection{Aggregate gross value added and sectoral value added}

Our analysis focuses on those MED countries whose Gross Value Added (GVA) and industry Value Added (VA) data are available from the 1970's. We have also excluded countries where conflicts and political turmoils have generated structural breaks and outliers in aggregate GVA and industry VA. Algeria and Libya have been also dropped because, being OPEC members, the oil supply shocks measure adopted in our study would not be exogenous to their economies. This leaves us with a total of eight MED countries: Egypt, France, Greece, Israel, Italy, Morocco, Spain, and Turkey.

The presence of Egypt among the selected MED countries is particularly important for at least three reasons. First, it is the only oilproducing country in our sample, although its production is too small to affect oil prices. ${ }^{3}$ Second, it is a developing, low-income country, as Morocco. Third, unlike Morocco, Egypt's energy intensity is extremely high.

GVA for these eight countries has been sourced from the National Accounts Main Aggregates Database, maintained by UN Statistics Division.

The same database also provides VA by type of economic activity. In particular, we are interested in studying the impact of exogenous oil supply shocks on the VA for the following five industries: Agriculture (ISIC A-B: Agriculture, Hunting, Forestry, Fishing); Manufacturing (ISIC C-E: Mining, Manufacturing, Utilities); Construction (ISIC F); Commerce (ISIC G-H: Wholesale, Retail trade, Restaurants and Hotels); Transport (ISIC I: Transport, Storage and Communication). ${ }^{4}$ All variables are annual, cover the period 1970-2015 and are expressed in US dollars at constant 2005 prices. $^{5}$

Per capita real GVA in 2015 for the selected MED countries is shown in the last column of Table 1. The North-South divide is evident. The MED-North African (NA) countries, i.e. Egypt and Morocco, have the lowest per capita GVA, while the MED-EU countries have the highest levels of per capita GVA. Columns (a)-(e) in Table 1 illustrate how GVA is distributed across industries. On this respect, the MED-NA countries have the highest share of GVA produced in Agriculture.

\subsection{Energy dependence and energy intensity}

The degree of energy dependence, namely the extent to which an economy relies upon imports in order to meet its energy needs, is an important factor to explain how different countries react to oil supply shocks. Energy dependence in 2014 is shown in Fig. 1 and is given by net energy imports, expressed as a percentage of energy use. Net energy imports are calculated as the difference between energy use and production, which are both measured in oil equivalents. A negative value, such as $-7 \%$ for Egypt, indicates that the country is a net exporter.

\footnotetext{
${ }^{3}$ We have collected a sizable body of empirical evidence supporting our view that Egypt can be considered an oil-price taker. First, while on average over the 1973-2015 period OPEC countries accounted for about $41 \%$ of world crude oil production, Egypt represents only $1 \%$ of global crude oil production. Second, even when compared with selected OPEC countries responsible for the most significant exogenous oil production shocks in the 1973-2015 period, Egypt's share of world oil production is small. Third, Egypt's crude oil production does not Granger cause neither OPEC, nor world production. The detailed results of our analysis are available from the authors upon request.

${ }^{4}$ ISIC is the International Standard Industrial Classification code defined by the UN Statistics Division. A sixth category, namely Other Activities (ISIC J-P), is also available. However, we have decided to exclude this category from the empirical analysis, since it comprises highly heterogeneous industries with a low degree of energy intensity, such as: Information and Communication; Financial and Insurance Activities; Real Estate Activities; Professional, Scientific and Technical Activities; Administrative and Support Service Activities; Public Administration and Defense; Education.

${ }^{5}$ At the moment of the revision of this paper, the last available year of data is 2015 . Figures showing the dynamics of GVA and sectoral GVA over time are reported in the Appendix.
} 
Table 1

Per-capita real gross value added and its components in 2015.

\begin{tabular}{lllllll}
\hline & \multicolumn{5}{l}{ VA by kind of economic activity as \% of GVA } & \\
\cline { 2 - 5 } Country & (a) & (b) & (c) & (d) & (e) & per capita GVA \\
\hline Egypt & 13.1 & 30.4 & 7.0 & 14.5 & 14.0 & 1467 \\
France & 1.8 & 14.8 & 4.3 & 13.7 & 11.2 & 32,648 \\
Greece & 5.0 & 10.9 & 3.5 & 15.3 & 10.2 & 16,640 \\
Israel & 1.2 & 17.7 & 5.5 & 9.9 & 15.6 & 22,059 \\
Italy & 2.4 & 18.9 & 4.2 & 16.0 & 9.7 & 26,388 \\
Morocco & 16.2 & 20.0 & 6.2 & 11.1 & 9.5 & 2496 \\
Spain & 3.2 & 16.9 & 6.3 & 18.7 & 9.9 & 23,622 \\
Turkey & 8.8 & 23.1 & 4.8 & 15.6 & 16.0 & 8108 \\
\hline
\end{tabular}

Notes: columns (a-e) show real Value Added (VA) by kind of economic activity as a percentage of Gross Value Added (GVA), while the last column displays per-capita real GVA in 2015. VA is available for the following industries: (a) Agriculture, hunting, forestry, fishing, (b) Mining, Manufacturing, Utilities, (c) Construction, (d) Wholesale, retail trade, restaurants and hotels, (e) Transport, storage and communication. The row sum of percentages in columns (a-e) is not equal to 100 in that the contribution of "Other activities" to GVA is not shown. Source: United Nations, Statistics Division - National Accounts Main Aggregates. the least energy dependent countries among net importers. Italy follows Morocco with $75 \%$ of energy derived from imports.

The way an oil supply shock impacts on a country's economy not only is influenced by its reliance on imported energy, but also it does depend on the quantity of energy required per unit output. Energy intensity in 2014 and its difference in the 1971-2014 period are shown in Fig. 2. Egypt, Morocco and Turkey are the countries with the highest degree of energy intensity. However, while the economy of Morocco currently requires less energy per unit output than in 1971, the production of goods and services has become more energy intense both in Egypt and Turkey. With the exception of Greece, the remaining countries have experienced a reduction in energy intensity, with France leading the group of virtuous economies. ${ }^{6}$

\subsection{Exogenous oil supply shocks}

We measure exogenous shocks to the supply of crude oil in OPEC member countries as the difference between the observed crude oil production level and a counterfactual level of crude oil production in countries where specific geo-political events have led to an oil pro-

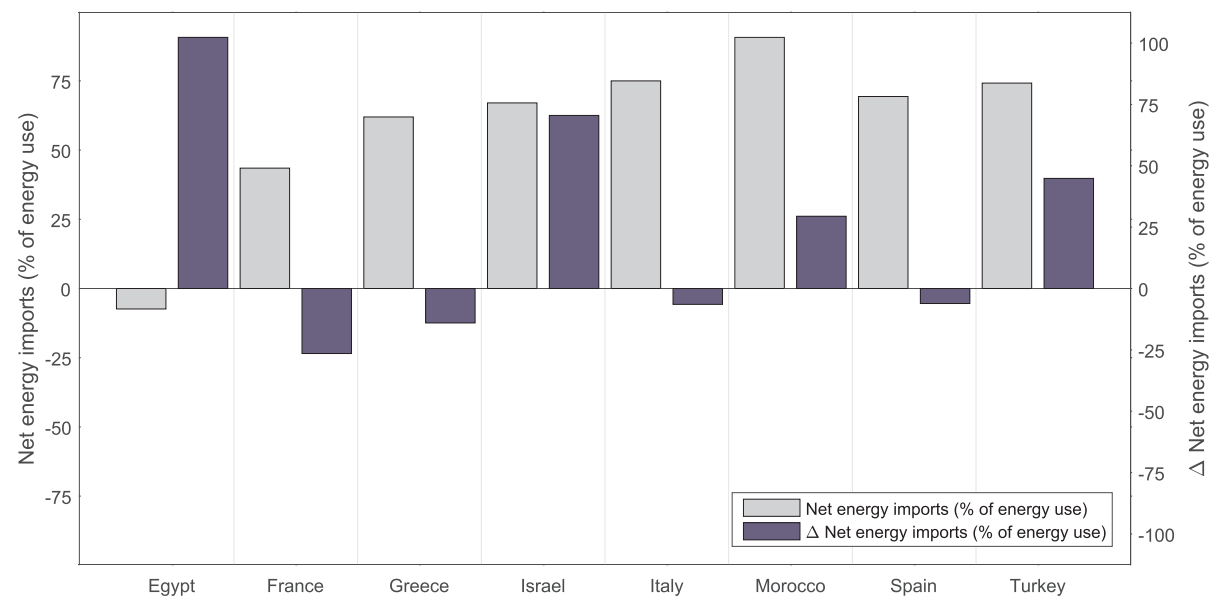

Fig. 1. Energy dependence: net energy imports (\% of energy use), Notes: Energy dependence is expressed by net energy imports as a percentage of energy use. Net energy imports are calculated as the difference between energy use and production, both measured in oil equivalents. A negative value indicates that the country is a net exporter. Data for Egypt and Morocco are available for the 1971-2014 period. Data for Israel start in 1971. Since the 2015 value is not available for all countries, in panel (a) we show the 2014 value. Source: The World Bank - World Development Indicators (http://wdi.worldbank.org/ table/3.8).

(a) Energy dependence in 2014 (left axis) and change in energy dependence 1971-2014 (right axis).

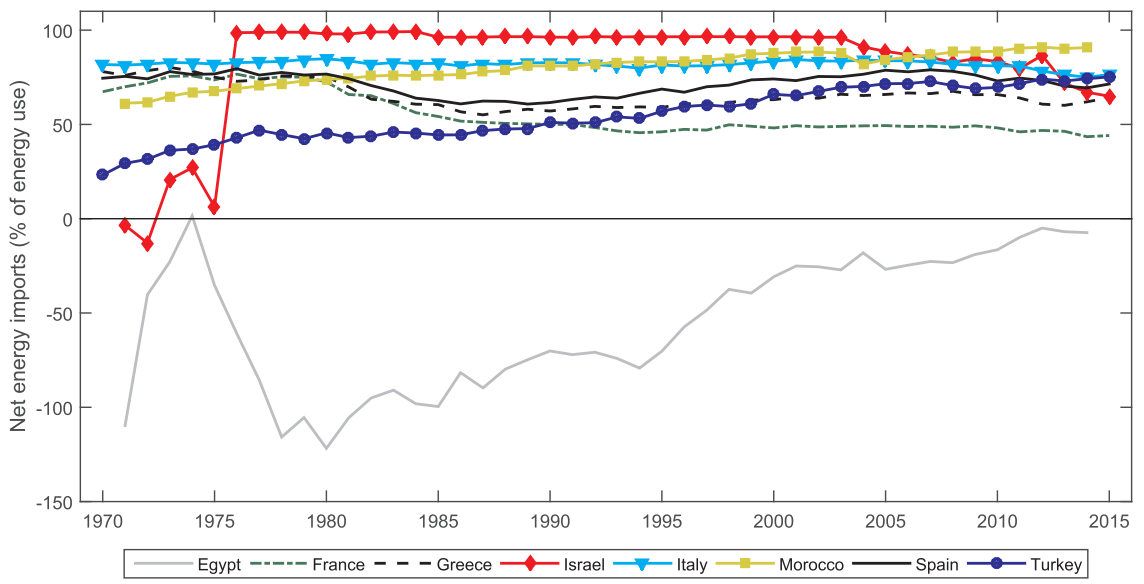

(b) Energy Dependence 1975-2015

A joint inspection of Table 1 and Fig. 1 reveals that in 2015 Egypt is the only net energy exporter among the selected MED countries and has the highest share of GVA associated to Manufacturing, which includes the petroleum industry.

It is evident that Morocco and France are, respectively, the most and duction shortfall (Kilian, 2008b). Since the original series of exogenous

\footnotetext{
${ }^{6}$ The impact of oil supply shocks in different industries is also expected to depend on the level of energy intensity, although energy intensity data at industry level are not available for the countries under scrutiny.
} 


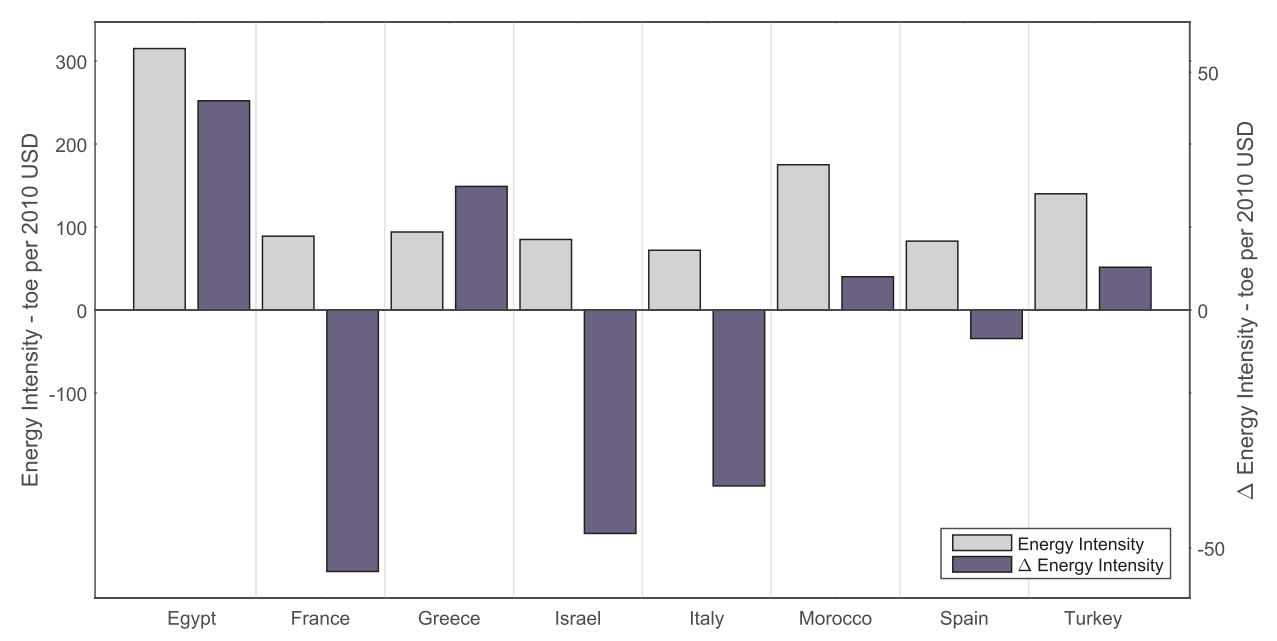

(a) Energy intensity in 2014 (left axis) and change in energy intensity 1971-2014 (right axis).
Fig. 2. Energy intensity, Notes: energy intensity is given by total primary energy consumption per dollar of Gross Domestic Product and is expressed in toe per thousand 2010 USD PPP. Data for Egypt and Morocco are available for the 1971-2014 period. Data for Israel start in 1971. Since data are not available for all countries over the entire 1970-2015, in panel (a) we report the change in energy intensity, denoted as $\Delta$ Energy Intensity, between 1971 and 2014 and in panel (b) we normalize the 1971 value to 100. Source: Enerdata.

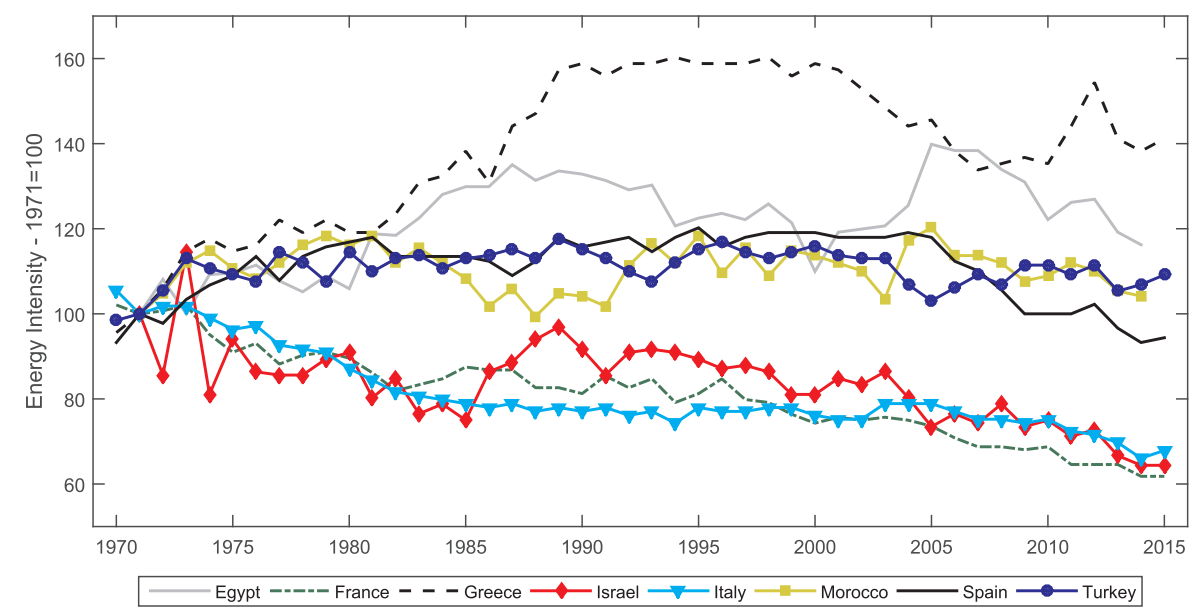

(b) Energy Intensity 1975-2015 (1971=100).

oil supply shocks due to Kilian (2008b) ends in September 2004, we have updated it to cover the period January 1970 - December 2015. This time span includes the crude oil production shortfall due to the Libyan Civil War of February 2011. During 2011, the shortfall due to this geo-political has reached over 1.5 millions barrels per day (see also Bastianin and Manera, 2017). ${ }^{7}$

The counterfactual series is defined as the level of production that would have been observed in the absence of the exogenous events which are responsible for the crude oil production shortfall. It is obtained by using the average growth rate of production in countries which are not hit by those geo-political events to forecast the pre-events production level on subsequent periods. Exogenous crude oil production shortfalls are then aggregated over countries, expressed as a percent of world crude oil production and transformed in first differences.

Our measure of exogenous oil supply shocks is based on monthly production data available from the Energy Information Administration

\footnotetext{
${ }^{7}$ As of June 2017, OPEC has a total of 14 member countries: Algeria, Angola, Ecuador, Equatorial Guinea, Gabon, Iran, Iraq, Kuwait, Libya, Nigeria, Qatar, Saudi Arabia, United Arab Emirates and Venezuela. This list is different from that in Kilian (2008a, 2008b). Specifically, Angola joined OPEC in 2007, while Ecuador suspended its membership from December 1992 until October 2007. Notwithstanding small numerical discrepancies, Alquist and Coibion (2014) show that the correlation between the original shock measured by Kilian (2008b) and the updated series of Bastianin and Manera (2017) is very close to one.
}

and its construction is detailed in Kilian (2008a, 2008b); Bastianin and Manera (2017) and in the Appendix of this paper. The dynamics of this series, aggregated at annual sampling frequency by cumulating monthly observations, is shown in Fig. 3, that also reports a set of vertical dashed lines that identify key oil dates used in construction of the series. The production shortfall associated with the Libyan Civil War is represented by a trough corresponding to $-1.6 \%$ of world crude oil production. Compared to previous episodes, the magnitude of this shortfall is small. For instance, the 2002 civil unrest in Venezuela has led to a shortfall equivalent to $-3 \%$ of world oil production.

The assumption of exogenous oil supply shocks is reasonable in this context, since the selected MED countries are too small to affect oil prices with their economic performance, although their economies are affected by the price of oil. Thus, in our model oil prices affect countries economic performance, but not vice-versa.

Other measures of exogenous shocks to the supply of crude oil are available in the literature. These proxies can be grouped into three broad classes: price-based, production-based and model-based. Hamilton (1996) and Mork (1989) introduced a price-based proxy known as Net Oil Price Increase (NOPI). However, the NOPI fails to capture exogenous oil supply shocks in correspondence of specific events, such as the Libyan Civil War, and tends to attribute oil price increases to production shortfalls, although they should be related to pressures on the demand side. A case in point is the spike in correspondence of the 2007-09 recession (see the bottom-right corner of 

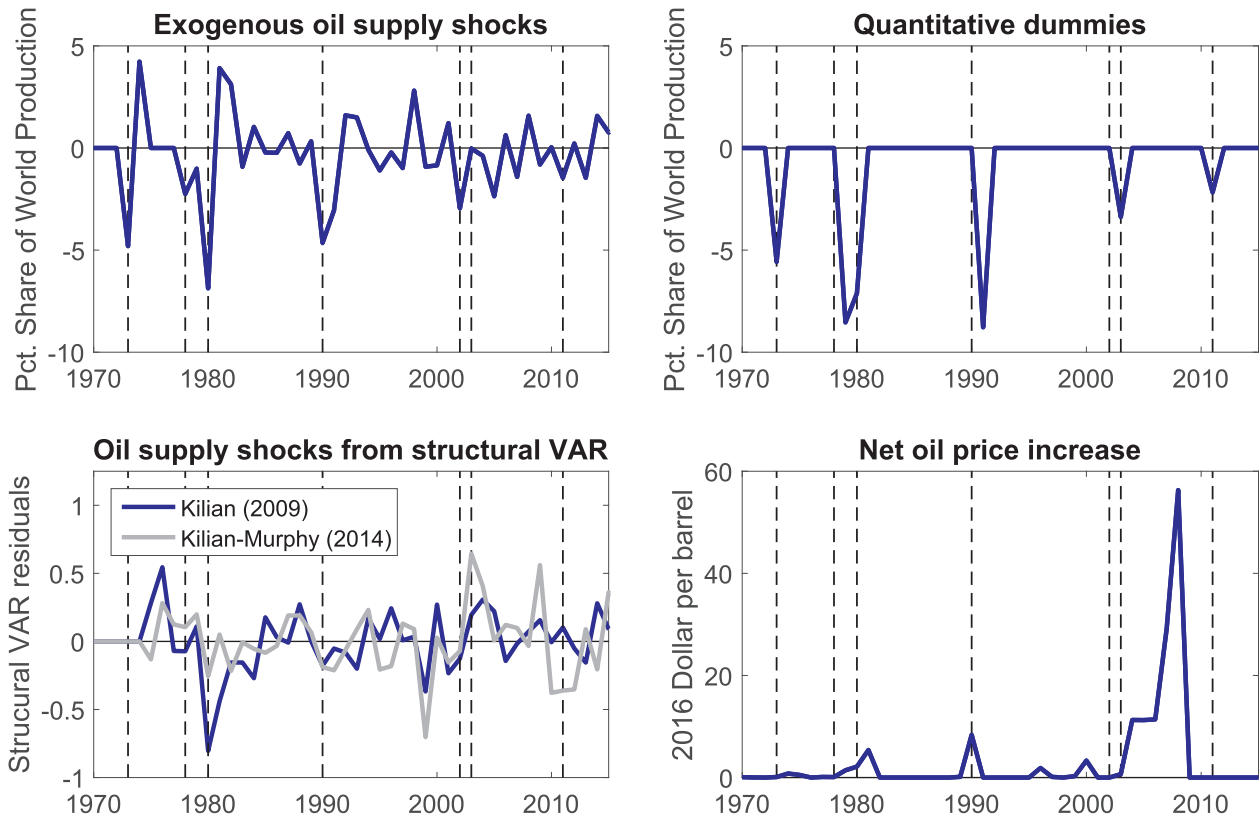

Fig. 3. Measure of exogenous oil supply shocks: 1970-2015, Notes: the figure shows the measure of exogenous oil supply shocks due to Kilian (2008b) (top left); the quantitative dummy measure due to Hamilton (2003) (top right); oil supply shocks derived from structural VAR models due to Kilian (2009) and Kilian and Murphy (2014) (bottom left); the net oil price increase measure (bottom right). The vertical dashed lines identify key oil dates used in construction the series shown in the top graphs: October 1973 (Yom Kippur War and Arab oil embargo), October 1978 (Iranian revolution), September 1980 (Iran-Iraq War), August 1990 (Persian Gulf War), December 2002 (Civil unrest in Venezuela), March 2003 (Iraq War), February 2011 (Libyan Civil War). See the Appendix for more details on the construction of these series.
Fig. 3).

A production-based proxy of exogenous oil supply shocks that exploits drops in the level of crude oil production around key events in OPEC countries is the so-called "Quantitative Dummy" series of Hamilton (2003) (top-right corner of Fig. 3). The main difference with the measure used in our paper is that the "Quantitative Dummy" series does not allow for positive supply shocks.

Model-based oil supply shock proxies can be derived from structural Vector AutoRegressive (VAR) models of the global market for crude oil, such as Kilian (2009) and Kilian and Murphy (2014). Structural residuals obtained from the production equation of these models are shown in the bottom-left corner of Fig. 3. Although these series are qualitatively similar to the measure used in this paper, they are generated regressors, hence their standard errors are unreliable. Moreover, their dynamics depends upon the identifying assumptions of the underlying structural VAR model.

\section{Methodology}

Let $Y_{t}$ be the level of economic activity, measured either by aggregate GVA or by sectoral VA, for a given MED country and define $y_{t} \equiv \log \left(Y_{t}\right)$. We compute the percentage growth rate of $y_{t}$ as $\Delta y_{t}=100 \times\left(y_{t}-y_{t-1}\right)$. To study the effects of exogenous oil supply shocks, $x_{t}$, on economic growth we use the following Distributed Lag (DL) model:

$\Delta y_{t}=\alpha+\sum_{j=0}^{H} \beta_{j} x_{t-j}+\varepsilon_{t}$

The model is estimated with Ordinary Least Squares (OLS), while inference is based upon standard errors computed with block-bootstrap methods, so as to deal with the possibility of serial correlation in the error terms $\varepsilon_{t}$.

In model (1) the OLS estimate of $\beta_{j}$ corresponds to the estimate of the impulse response at horizon $j$, whereas the lag order of the model, set to $H=5$ years, represents the maximum horizon. While $\widehat{\beta}_{j}$ is the estimated response of real GVA (or industry VA) growth to a unit change in $x_{t}$ at horizon $j$, the response of the level of GVA (or industry VA) to a unit change in $x_{t}$ at horizon $h$ can be obtained by cumulating the OLS estimates of $\beta_{j}$ as $\sum_{j=0}^{h} \widehat{\beta_{j}}, h \leq H$.

Model (1) rests on the assumption that $x_{t}$ is pre-determined with respect to macroeconomic conditions in a given country. Pre- determinedness of $x_{t}$ implies that there is no instantaneous feedback from the level of economic activity in the selected MED countries to crude oil production in OPEC countries. This working hypothesis has been extensively used in the literature (Kilian, 2008b; Bastianin et al., 2016). Tests for the exclusion of $x_{t}$ show that $x_{t}$ can be eliminated from model (1) for all countries. Moreover, we also show that all GVA and sectoral VA series are stationary and that empirical evidence supports the absence of Granger causality running from $x_{t}$ to $\Delta y_{t}{ }^{8}$

\section{Results and discussion}

\subsection{The impacts of exogenous oil supply shocks on aggregate real Gross Value Added}

The response of real GVA growth to a permanent $1 \%$ reduction in global crude oil production is presented in Fig. 4. Moreover, the second and third columns in the top panel of Table 2 show the date and the magnitude of the trough in the response of real GVA growth to oil supply shocks. The date of the trough is the number of years needed by the estimated impulse response function to reach its minimum, after an oil supply shock has hit the economy of a given country. The corresponding level of real GVA is shown in the bottom panel of Table 2 and in Fig. 5.

Egypt, which is one of the two MED-NA countries in our sample, experiences a reduction in real GVA growth on the first year after the oil supply shock. However, Table 2 shows that the $-0.2 \%$ variation in real GVA is statistically indistinguishable from zero. A joint inspection of Figs. 4 and 5 highlights that in Egypt neither the growth rate, nor the level of real GVA do significantly react to a permanent $1 \%$ reduction in global oil production. Egypt has two peculiarities: it is the only net energy exporter and it has the most energy intense economy within the selected MED countries. Therefore, our results seem to suggest that, for Egypt, the benefits of not depending on imported crude oil compensate the costs of having a very energy-intense economy. The balance of the two effects is to virtually cancel out the impact of oil supply shocks on the Egyptian economy.

Results for Morocco, the second selected MED-NA country, are

\footnotetext{
${ }^{8}$ Details on the tests for the exclusion of $x_{t}$, the model selection procedure, and the analysis of the statistical properties of the macroeconomic series are reported in the Appendix.
} 

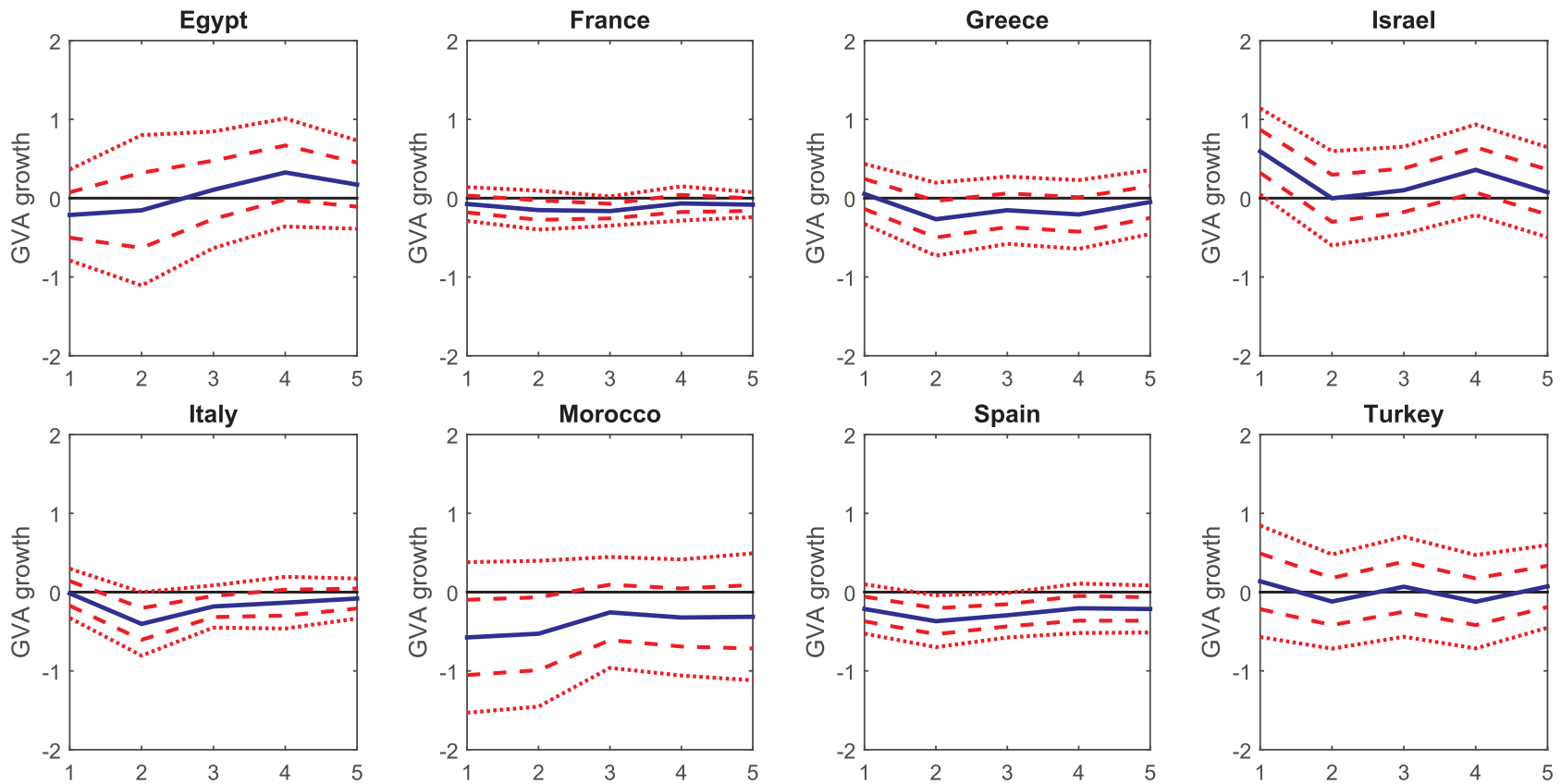

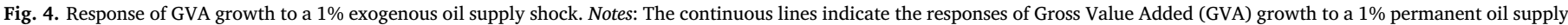

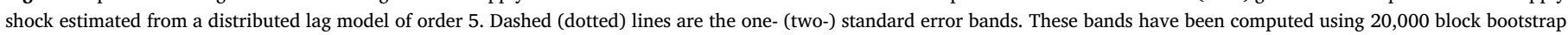
samples (with a block size of 2 years), in order to account for possible serial correlation in the error term.

Table 2

Dates and magnitudes of troughs of real GVA (VA) growth and real GVA (VA) responses to a 1\% exogenous oil supply shock.

Panel a. Real GVA and real VA growth

$$
\text { GVA growth } \quad \text { VA growth }
$$

\begin{tabular}{|c|c|c|c|c|c|c|c|c|c|}
\hline \multicolumn{2}{|c|}{ (a) } & \multicolumn{2}{|c|}{ (b) } & \multicolumn{2}{|c|}{ (c) } & \multicolumn{2}{|c|}{ (d) } & \multicolumn{2}{|c|}{ (e) } \\
\hline $\mathrm{t}$ & $\%$ & $\mathrm{t}$ & $\%$ & $\mathrm{t}$ & $\%$ & $\mathrm{t}$ & $\%$ & $\mathrm{t}$ & $\%$ \\
\hline 5 & $-0.20^{*}$ & 2 & $-1.27^{*}$ & 1 & -0.54 & 1 & $-0.60^{*}$ & 2 & -0.50 \\
\hline 3 & $-0.89^{*}$ & 2 & $-0.43^{* *}$ & 3 & $-0.45^{*}$ & 3 & $-0.31^{*}$ & 4 & $-0.40^{*}$ \\
\hline 4 & -0.53 & 1 & $-0.53^{*}$ & 3 & $-1.38^{*}$ & 2 & $-0.44^{*}$ & 2 & -0.36 \\
\hline 3 & $-1.38^{*}$ & 2 & 0.05 & 5 & $-1.55^{*}$ & 3 & -0.24 & 4 & $-0.90^{*}$ \\
\hline 5 & -0.14 & 2 & $-0.93^{* * *}$ & 4 & $-0.32^{*}$ & 2 & $-0.35^{*}$ & 4 & $-0.35^{*}$ \\
\hline 1 & $-3.14^{*}$ & 2 & $-0.37^{*}$ & 5 & -0.29 & 1 & -0.32 & 3 & -0.03 \\
\hline 1 & $-0.70^{*}$ & 2 & $-0.63^{k * *}$ & 2 & $-0.79^{*}$ & 2 & $-0.22^{*}$ & 2 & $-0.30^{*}$ \\
\hline 4 & $-0.41^{*}$ & 2 & -0.24 & 2 & $-0.93^{*}$ & 4 & -0.07 & 2 & -0.05 \\
\hline
\end{tabular}

Panel b. Real GVA and real VA

\section{VA}

\begin{tabular}{|c|c|c|c|c|c|c|c|c|c|c|c|c|}
\hline \multirow[b]{3}{*}{ Country } & \multirow{2}{*}{\multicolumn{2}{|c|}{ GVA }} & & & & & & & & & & \\
\hline & & & \multicolumn{2}{|c|}{ (a) } & \multicolumn{2}{|c|}{ (b) } & \multicolumn{2}{|c|}{ (c) } & \multicolumn{2}{|c|}{ (d) } & \multicolumn{2}{|c|}{ (e) } \\
\hline & $\mathrm{t}$ & $\%$ & $\mathrm{t}$ & $\%$ & $\mathrm{t}$ & $\%$ & $\mathrm{t}$ & $\%$ & $\mathrm{t}$ & $\%$ & $\mathrm{t}$ & $\%$ \\
\hline Egypt & 2 & -0.37 & 5 & -0.17 & 2 & $-1.26^{*}$ & 1 & -0.54 & 1 & $-0.60^{*}$ & 3 & -1.02 \\
\hline France & 5 & $-0.54^{*}$ & 1 & $-0.55^{*}$ & 5 & $-1.11^{*}$ & 5 & $-1.27^{*}$ & 5 & $-1.12^{\text {*k* }}$ & 5 & $-1.53^{* * *}$ \\
\hline Greece & 5 & -0.62 & 4 & -0.12 & 5 & $-2.09^{*}$ & 5 & $-4.77^{*}$ & 5 & $-1.39^{*}$ & 4 & -0.10 \\
\hline Israel & 2 & 0.47 & 3 & -1.17 & 1 & $0.81^{*}$ & 1 & $3.74^{* * k}$ & 1 & 0.01 & 4 & $-1.64^{*}$ \\
\hline Italy & 5 & $-0.82^{*}$ & 1 & 0.11 & 5 & $-1.54^{*}$ & 5 & -0.25 & 5 & -0.45 & 5 & $-1.15^{*}$ \\
\hline Morocco & 5 & $-2.00^{*}$ & 5 & $-9.67^{*}$ & 4 & $-0.71^{*}$ & 5 & -0.04 & 5 & $-1.06^{*}$ & 1 & 0.21 \\
\hline Spain & 5 & $-1.29^{* *}$ & 5 & $-2.36^{*}$ & 5 & $-1.77^{* * k}$ & 5 & $-2.84^{*}$ & 5 & $-0.53^{*}$ & 5 & $-0.72^{*}$ \\
\hline Turkey & 4 & -0.03 & 5 & $-0.96^{*}$ & 4 & 0.17 & 5 & -1.06 & 2 & 0.21 & 2 & 0.13 \\
\hline
\end{tabular}

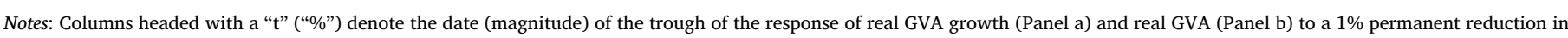

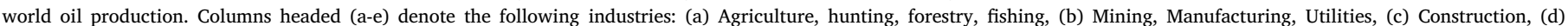

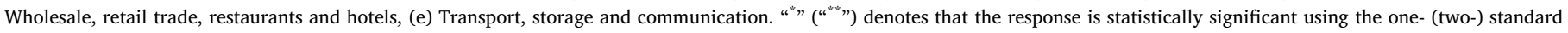
error bands.

completely different. As of 2014, Morocco was importing $91 \%$ of the energy used in the country and in that year it was second only to Egypt in terms of energy intensity. These two factors can probably explain the long-lasting reduction in real GVA growth observed in Fig. 4. The variation of real GVA reaches its minimum, $-0.57 \%$, a year after the economy is hit by the oil supply shock and remains statistically 

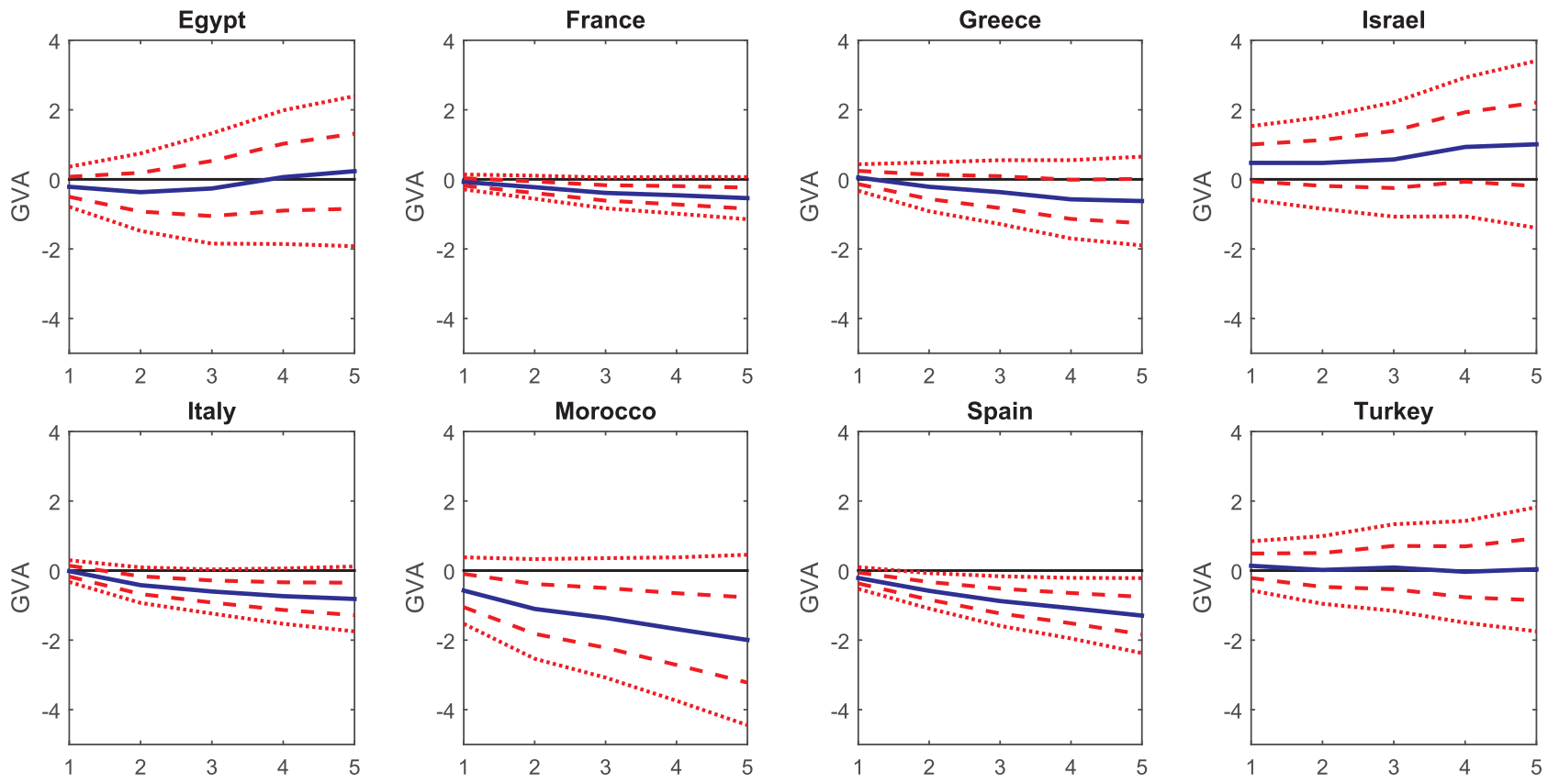

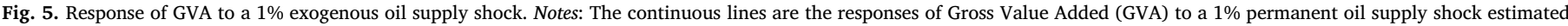

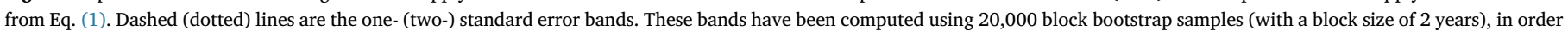
to account for possible serial correlation in the error term.

significant for two years, using the one-standard error bands. The bottom panels of Table 2 and Fig. 5 show that there is a reduction also in the level of real GVA. The response of real GVA gets to a minimum, $-2 \%$, five years after the exogenous oil supply disruption and is statistically significant using the one-standard error bands.

For all the MED-EU countries, namely France, Greece, Italy and Spain, an unexpected reduction in global oil production leads to a decrease in real GVA growth two or three years after the shock. This reduction, in all cases, is also statistically significant, using the onestandard error bands. This finding suggests the existence of similarities among these countries, possibly due to the operation of common factors, such as the influence of a common monetary policy.

France, which exhibits one of the lowest degree of energy intensity in 2014 and is the least energy dependent country among net energy importers (it imports $46 \%$ of its energy), experiences the smallest reduction in growth $(-0.16 \%)$. Spain and Italy are similar in terms of energy dependence, since in 2014 both countries imported between $69 \%$ and $75 \%$ of the energy they used, and respond to an oil supply shock with a reduction in real GVA growth close to $-0.4 \%$ in the second year. This negative effect on growth is, in both cases, statistically significant using the two-standard error bands. The effect of an oil production disruption on the real GVA growth of Greece, which imports $62 \%$ of its energy, is $-0.27 \%$.

As we have documented, all the MED-EU countries experience oil supply shocks in a similar fashion, that is a negative and statistically significant effect on real GVA growth two years after the shock. Interestingly, the negative impact on growth increases with the degree of energy dependency of the economy.

Figs. 4 and 5 show that the responses of the two MED-ME countries in our sample, namely Turkey and Israel, although marginally positive on impact, are never statistically distinguishable from zero. This results can be interpreted as evidence of a possible non-linear relationship between oil price shocks and economic performance (Berument et al., 2010).
4.2. The impacts of exogenous oil supply shocks on real Value Added for selected industries

The analysis of the impacts of a disruption in global oil production on the level and the growth rate of real VA in different branches of economic activity might help disentangling how the selected MED countries cope with oil supply shocks. Comments to the empirical results account for sectors' specificities as well as countries' characteristics, as illustrated in Sections 2.1 and 2.2. ${ }^{9}$

The top panel of Table 2 shows that in Egypt three industries exhibit a statistically significant reduction of real VA growth using the onestandard error bands, namely Agriculture, Manufacturing and Commerce (see columns (a), (b) and (d)). In the first case, the trough, equal to $-0.20 \%$, is reached five years after the shock, in the second case real VA takes two years to reach the minimum, while in the third case it takes only one year. The results confirm the characteristics of Egypt, which, among the scrutinized countries, presents the largest share of real GVA allocated to Manufacturing (30\%), the second largest share of real GVA attributed to Agriculture (13\%) and the highest degree of energy intensity. However, the response of the level of real VA in Agriculture is not statistically distinguishable from zero (see column (a) in the bottom panel of Table 2).

Morocco shows the largest response of the agricultural real VA growth among the countries under analysis, that is a statistically significant trough of $-3 \%$ one year after the shock. This finding can be explained in terms of the relative weight of Moroccan Agriculture (16\% of real GVA), which is the largest among the MED countries. Manufacturing experiences a $-0.4 \%$ reduction in the real VA growth two years after the crude oil production disruption. In both cases the response is statistically significant using the one-standard error bands. This evidence matches with the main features of Morocco, which is the most energy dependent economy among the net importer countries analyzed in our paper and shows the second highest degree of energy intensity after Egypt.

Several common patterns characterize the responses of real VA growth in Manufacturing. With the exception of Greece, which has the

${ }^{9}$ To save space, impulse responses are shown in the Appendix. 
lowest share of real GVA attributed to this sector (11\%), the trough in the real VA growth in Manufacturing is always recorded two years after the shock. Moreover, using the one-standard error bands, the negative effect of an oil supply shock on the growth rate of real VA in Manufacturing is statistically significant for all the MED-EU countries. Lastly, we notice that, in the case of France, Spain and Italy, the response of the level of VA in Manufacturing is negative and statistically significant (using the one-standard error bands) up to five years after the oil supply shock. The explanation of these results can be found in the composition of the Manufacturing sector, which includes the petroleum industry and therefore it is more exposed to the effects of oil price shocks.

Column (d) in panel (a) of Table 2 illustrates that oil supply shocks have negative and often statistically significant effects on Commerce in most MED countries. The common behavior of this sector across different MED economies indirectly testifies the existence of strong commercial links within the MED region, which are sustained by specific policy interventions such as the Euro-Mediterranean Free Trade Agreements (Escribano, 2009).

Construction is negatively influenced by oil supply shocks across the selected MED countries, although differences are documented in the reaction of the industry VA growth with respect to the industry VA level (Table 2, panel (b), column (c)). For instance, the industry VA growth significantly decreases in six countries out of eight, while the level of industry VA significantly declines in three of the analyzed countries. The only exception is represented by the positive and significant increase of the level of activity in the Israeli Construction sector, which can be explained in the light of the constant support to the development of this industry put forth by the Israeli Government during the last decades. ${ }^{10}$ One possible interpretation of the reaction to oil supply shocks of the Construction sector is the high degree of energy intensity of this industry, which accounts for $35 \%$ of total final energy consumption in some MED countries (OME, 2016).

Finally, we see from column (e) of Table 2 that Transport is negatively affected by a shock to the supply of crude oil. This finding is not surprising, since this sector accounts for a third of total energy consumption in the MED region, $95 \%$ of which is represented by oil products (OME, 2016). The magnitude of the (statistically significant) responses range from $-0.3 \%$ for Spain up to $-0.9 \%$ for Israel. This spectrum of results is motivated by the different characteristics of the Transport sectors across countries. In lower-/middle-income MED countries, for instance, the average retirement of vehicles is rather high (14 years or more, according to OME, 2016). Moreover, public transport is not yet fully developed in the MED region. Those examples demonstrate the urgency for more efficient private and public transport modes, which could contribute to mitigate the sensitivity of this sector to unexpected oil price changes.

\subsection{Robustness checks}

Since our data cover a long time period, all our findings might potentially be affected by the presence of structural breaks. Therefore, we have implemented a series of tests of the null of parameter stability. More precisely, we have tested the constancy of the $\beta$ parameters of model (1) using the Quandt Likelihood Ratio (QLR) approach of Andrews (1993). Two out of three QLR tests never reject the null hypothesis, while only one QLR specification suggests some parameter instability in correspondence to the recession years 2008 and 2009.

We have also assessed the robustness of our empirical findings to different measures of oil supply shocks. To this end, we have re-estimated model (1) using as explanatory variables the structural residuals

\footnotetext{
${ }^{10}$ See, for instance, the Israeli Government Resolution n. 2214 dated 12/8/2007. Source: Ministry of Construction and Housing, Israel. Web: http://www.moch.gov.il/ English/.
}

capturing "flow supply shocks" derived from the model of Kilian and Murphy (2014) (see the bottom-left corner of Fig. 3). The results obtained exhibit striking qualitative similarities with Figs. 4 and 5, which confirm our main conclusions about the responses of GVA to oil supply shocks. ${ }^{11}$

\section{Conclusions and policy implications}

The relationships between the EU and countries in the North African and Middle East region of the Mediterranean Sea are strategically important for energy firms operating in the area, as well as for the energy security of net energy importers.

In this paper we have shown that the degree of energy intensity and energy dependence influence how the selected Mediterranean economies react to an unexpected reduction in global crude oil production. The response of real Gross Value Added growth is negative and often statistically significant for net energy importers, while for net energy exporters (i.e. Egypt) it is not distinguishable from zero. This result holds for the aggregate economies, as well as for the selected industries.

In the case of the Mediterranean countries belonging to the $\mathrm{EU}$, several similarities emerge. Above all, the effects of an oil supply shock increase with the degree of energy dependence and countries experience shocks with the same timing.

Our results have a number of policy implications, which are in line with recent studies (Tagliapietra, 2016). First, the EU should rethink its policy approach in the Mediterranean region by introducing bilateral agreements aimed at reducing energy dependence and supporting energy efficiency at country level. ${ }^{12}$ Second, the EU should stimulate projects on the efficient use of energy in the area through a more direct involvement of the multilateral financial institution which has more potential in the Mediterranean region, namely the European Bank for Reconstruction and Development (EBRD). On this respect, the EBRD could create financial opportunities in the form of public-private partnerships with the government of a selected Mediterranean country and international energy companies operating in that country. Those agreement could contribute to build up a guarantee system which is necessary for global investors to enter the local energy sector. Third, European financial markets should promote specific financial instruments aimed at reducing political, technological, financial and currency risks, which are endemic to energy efficiency projects in the Mediterranean region and which are different, depending on the country considered. ${ }^{13}$ Fourth, international investors interested in the Mediterranean energy markets for portfolio diversification should take into account, before formulating their investment plans, the exposure of each country to oil supply shocks, as well as the different reactions of specific sectors of economic activity within each country.

These results suggest that initiatives aimed at strengthening the

\footnotetext{
${ }^{11}$ Details on each robustness check, as well as associated tables and figures, are reported in the Appendix.

12 During the last two decades the EU policy towards the Mediterranean countries has provided several examples of bilateral and multi-bilateral agreements, first within the framework of the Euro-Mediterranean Partnership (EMP), then with the European Neighbourhood Policy (ENP) and the Union for Mediterranean (UfM), finally with the Global Strategy for European Union's Foreign and Security Policy (Aliboni, 2016). Energy saving policies aimed at reducing energy dependence in the Mediterranean countries are illustrated in OME (2016). For instance, substantial energy savings are expected in: the Construction sector (residential and tertiary sectors), through the adoption of tighter efficiency standards for new dwellings and electrical equipment (including household appliances, as well as cooling and heating systems); the Manufacturing sector, through standards and cleaner and more efficient technologies; the Transportation sector, through energy policies and measures for private transport (more efficient vehicles), the design of new cities and the re-organization of public transport.

${ }^{13}$ Examples of financial instruments aimed at promoting specific investments in the Mediterranean region are: loans, risk capital and collaterals, following the behavior of the BERS, the European Investment Bank and the FEMIP Trust Fund; government bonds with risk/return profiles tailored for long-term private investors; unlisted securities and mezzanine capital, along the direction traced by InfraMed Infrastructure (Bruno and Reviglio, 2016).
} 
collaboration between the EU and other Mediterranean countries, net energy exporters in particular, might be crucial for improving energy security in the region. Moreover, integration efforts such as the development of the "EU-South Mediterranean Energy Community" might help Mediterranean countries to reach other goals, such as the design of a common environmental policy in the area.

\section{Acknowledgments}

The authors wish to thank the Editor and two anonymous Referees for their invaluable comments and suggestions, which have significantly contributed to improve the quality of our paper. The authors would also like to thank Daniele Valenti for invaluable research assistance. The first author gratefully acknowledges financial support from the Italian Ministry of Education, Universities and Research [PRIN 2010-2011, n. 2010S2LHSE-001].

\section{Appendix A. Supplementary data}

Supplementary data associated with this article can be found in the online version at http://dx.doi.org/10.1016/j.enpol.2017.08.004.

\section{References}

Aliboni, R., 2016. Europe and the Mediterranean: the road to follow. Equilibri 2, 211-218.

Alloisio, I., Calliari, E., Tagliapietra, S., 2016. Marrakech: an Additional Push toward Euro-mediterranean Energy Cooperation. Equilibri, 2. 289-295.

Alquist, R., Coibion, O., 2014. Commodity-price comovement and global economic activity. NBER Working Papers 20003. National Bureau of Economic Research.

Andrews, D.W.K., 1993. Tests for parameter instability and structural change with unknown change point. Econometrica 821-856.

Bastianin, A., Conti, F., Manera, M., 2016. The impacts of oil price shocks on stock market volatility: evidence from the G7 countries. Energy Policy 98, 160-169.

Bastianin A., Manera M. (2017), How does stock market volatility react to oil shocks? Macroeconomic Dynamics, published online, 16 january 2017 (ISSN: 1365-1005, DOI: http://dx.doi.org/10.1017/S1365100516000353).

Baumeister, C., Peersman, G., Robays, I.V., 2010. The economic consequences of oil shocks: differences across countries and time. In: Fry, R., Jones, C., Kent, C. (Eds.), Inflation in an Era of Relative Price Shocks. Reserve Bank of Australia, Sidney, pp. 91-128.

Berument, M.H., Ceylan, N.B., Dogan, N., 2010. The impact of oil price shocks on the economic growth of selected MENA countries. Energy J. 31, 149-176.

Bruno, C., Reviglio, E., 2016. Funding sustainable energy in the Mediterranean. A Junker plan for the region? Equilibri 2, 310-318.

Cunado, J., Jo, S., de Grazia, F.P., 2015. Macroeconomic impacts of oil price shocks in Asian economies. Energy Policy 86, 867-879.

Escribano, G., 2009.The evolution of the Euro-Mediterranean trade framework. IEMed Yearbook 2009. European Institute of the Mediterranean. Available online at: 〈http://www.iemed.org/anuari/2009/aarticles/a101.pdf:101-108〉.

European Commission, 8 March 2011. A partnership for democracy and shared prosperity with the Southern Mediterranean. COM, 2011, 200 Final. Brussels.

Fakhri, H., Bulut, C., Suleymanov, E., 2017. Review of energy-growth nexus: a panel analysis for ten Eurasian oil exporting countries. Renew. Sustain. Energy Rev. 73, 369-386.

Güntner, J.H.F., 2014. How do international stock markets respond to oil demand and supply shocks? Macroecon. Dyn. 18 (8), 1657-1682.

Hafner, M., Tagliapietra, S., 2016. Relaunching Euro-Mediterranean cooperation through energy. Equilibri 2, 207-210.

Hamilton, J.D., 1996. This is what happened to the oil price-macroeconomy relationship. J. Monet. Econ. 38 (2), 215-220.

Hamilton, J.D., 2003. What is an oil shock? J. Econ. 113 (2), 363-398.

Hamilton, J.D., 2013. Historical oil shocks. In: Parker, R.E., Whaples, R. (Eds.), Routledge Handbook of Major Events in Economic History. Routledge Taylor and Francis Group, New York, pp. 239-265.

Jiménez-Rodríguez, R., Sánchez, M., 2005. Oil price shocks and real GDP growth: empirical evidence for some OECD countries. Appl. Econ. 37 (2), 201-228.

Kilian, L., 2008a. A comparison of the effects of exogenous oil supply shocks on output and inflation in the G7 countries. J. Eur. Econ. Assoc. 6 (1), 78-121.

Kilian, L., 2008b. Exogenous oil supply shocks: How big are they and how much do they matter for the U.S. economy? Rev. Econ. Stat. 90 (2), 216-240.

Kilian, L., 2009. Not all oil price shocks are alike: disentangling demand and supply shocks in the crude oil market. Am. Econ. Rev. 99 (3), 1053-1069.

Kilian, L., Murphy, D.P., 2014. The role of inventories and speculative trading in the global market for crude oil. J. Appl. Econ. 29 (3), 454-478.

Mork, K.A., 1989. Oil and the macroeconomy when prices go up and down: an extension of Hamilton's results. J. Political Econ. 97 (3), 740-744.

Moshiri, S., Banihashem, A., 2012. Asymmetric effects of oil price shocks on economic growth of oil-exporting countries. USAEE Working Paper No. 12-140.

OME, 2016. Mediterranean Energy Transition: 2040 Scenario, Observatoire Méditerranéen de l'Energie. Available on line at: 〈http://www.ome.org/〉.

Santillán-Salgado, R.J., Venegas-Martínez, F., 2015. Impact of Oil Prices on Economic Growth in Latin American Oil Exporting Countries (1990-2014): a Panel Data Analysis. Available at SSRN: 〈https://ssrn.com/abstract $=2692024\rangle$ or http://dx.doi org/10.2139/ssrn.2692024.

Tagliapietra, S., 2016. Energy Relations in the Euro-Mediterranean: a Political Economy Perspective. Palgrave MacMillan.

Tholens, S., 2014. An EU-south Mediterranean energy community: the right policy for the right region? Int. Spect. 49 (2), 34-49.

UfM, 2016. UfM Ministerial Declaration on Energy, Union for the Mediterranean. Available on line at: 〈http://ufmsecretariat.org/〉. 